of the Piltdown relic by Mr. Alvan T. Marston, which appears in Discovery of January. Here the basis of argument is the character and arrangement of the teeth, in which it is maintained the jaw is anthropoid and not human. The form of the canines, it is said, points to a gap between canines and incisors and an outside bite of the former, such as are found in the apes, but never appear in man, even in such an early and primitive form as Peking man. Similarly, such indications as are afforded by the Piltdown jaw on the order of eruption of the teeth point to the anthropoid, rather than the human, character of the dentition. The canine, instead of preceding the second molar, as in man, was here the last to erupt, and indeed, Mr. Marston infers, was still incompletely formed. Further, he concludes, the jaw shows no evidences of the adaptations for speech, for which capacity is to be inferred from the advanced character of the brain. When Prof. Weidenreich's promised monograph on the teeth of Sinanthropus appears, in view of the relatively large amount of evidence at his disposal, it may be anticipated that we shall learn whether the teeth show the variability, which he has found in the mandible, and whether it supports the evidence already available to Mr. Marston, on which he relies to no little extent in stating his case.

\section{France and its People}

IN "France : a Handbook for Beginners in French" (Cambridge: W. Heffer and Sons, Ltd. Pp. 48. 1s. net) are reproduced three lectures by Dr. Cloudesley Brereton, originally broadcast in Great Britain in December 1935 and January 1936 and afterwards repeated, at the invitation of the French Government, from Paris. The sub-title, in so far as it may tend to suggest that the pamphlet is unlikely to appeal to the general public, is misleading, for here is no mere catalogue of dry facts but a lively appreciation of the genius, to quote the author's own words, of a hard-working, cheerful, amiable, keen-witted, polished, social, artistic and, at bottom, spiritually. minded people. That it is eminently fitted to promote that mutual understanding and appreciation between nations which a strident modern nationalism threatens to stifle has been recognized by the judges entrusted with the awarding of the recently instituted "Prix internationaux du Tourisme". They have awarded to the author the second prize of 15,000 francs; the first prize, of 25,000 francs, having been awarded to Mrs. Brangwyn, an American, for "Everybody in Paris". As an example of Dr. Brereton's method may be quoted his comparison between French and English science teaching in secondary schools. Practical science is, he holds, rather neglected in the French lycée. "In the more abstract side of science, however, a very high standard is attained. Our schools possibly err in the other direction-somehow the glamour of science has rather been overshadowed by the excessive cult of the test tube in this country".

\section{Archæological Expedition to Nubia}

SIR ROBERT Mond's appeal on behalf of the archæological expedition to Nubia projected by the
Egypt Exploration Society merits, and no doubt will receive, full measure of support. The valuable work of investigation which the Society has carried out at Tell el-Amarna under its present concession from the Egyptian Government, on a site which might have been thought already to have yielded its precious material to the excavator, is a warrant that the expedition will spare no pains on the new sites to secure that nothing of moment is overlooked which may throw light on the history and culture of this little-known part of ancient Egyptian rule. As Sir Robert points out in his letter to The Times of January 4, the two sites which have been reserved provisionally for the Society, Sulb (Soleb) and Sesebi in Upper Nubia in the region of the Third Cataract of the Nile, will both throw further light on the Amarna age, upon which the Society has been engaged now for some years. Their comparative inaccessibility accounts for the fact that they have been little studied; but it is known that at both these fortress cities there are remains which date from the reigns of Amenophis III and Akhnaton. The temple of Sulb is in fact described by Breasted, as quoted by Sir Robert, as "the most important monument surviving in the Sudan, and one of the two greatest architectural works surviving in the Nile Valley, the other being the temple of Luxor . . . We have in Soleb, therefore, one of the first creations of the Empire". As the temple has on its walls running reliefs which depict scenes from the Sed festival, to celebrate which Amenophis caused this temple to be built, its investigation will supply information as to ritual and belief which is unique. Further, as the two fortresses probably occupied the sites of earlier Nubian towns, some data, at least, should be forthcoming bearing upon the earlier population of Nubia, which, it will be remembered, the late Sir Grafton Elliot Smith held to be of considerable moment in the understanding of the early racial history of ancient Egypt.

\section{Academy of Natural Sciences, Philadelphia}

IN the course of the current month, the Academy of Natural Sciences, Philadelphia, will issue invitations to an international symposium on early man and the origins of the human race which is to be held in Philadelphia on March 18-20. This symposium will. form part of the proceedings celebrating the one hundred and twenty-fifth anniversary of the foundation of the Academy. Among those who have already promised to contribute to the symposium are Dr. P. Teilhard de Chardin of China, Dr. Ralph von Koenigswald of Java, Dr. R. Broom of South Africa, Miss D. A. E. Garrod of Great Britain, and Dr. Kaj Birket-Smith of Denmark. The arrangement of the programme is in the hands of a committee which includes Dr. John C. Merriam, president of the Carnegie Institution, Washington, D.C., Dr. Edwin C. Conklin, vice-president of the Academy and president of the American Association for the Advancement of Science, Dr. George G. MacCurdy, director of the American School of Prehistoric Research, Dr. Hellmut de Terra of the Carnegie Institution and Dr. E. B. Howard, 